\title{
Mechanical Properties of Natural Fibre Reinforced Hybrid Composites
}

\author{
Chensong Dong
}

Department of Mechanical Engineering, Curtin University, GPO Box 1987, Perth, WA 6845, Australia

\begin{abstract}
A study on the hybrid composites reinforced by two types of short natural fibres is presented. The material properties of short natural fibre composites were obtained by Mori-Tanaka method. Three point bend test was simulated by the Classical Beam Theory (CBT) and Finite Element Analysis (FEA). Both asymmetric and sandwich hybrid composites were studied. From the results, the following conclusions can be drawn:
\end{abstract}

1. A general rule is that one lamina of higher stiffness should be placed on the tensile face of a hybrid composite in order to obtain improved flexural strength.

2. For the sandwich type hybrid composites, the higher stiffness material should be placed in the core and the lower stiffness material should be the skin.

Keywords: Natural fibre; hybrid; composites; flexural 


\section{Nomenclature}

a

A

$b$

C

$\overline{\mathbf{C}}$

$\mathrm{C}_{\mathrm{f}}$

$\mathbf{C}_{m}$

D

$E_{c}$

$E_{f}$

$E_{m}$

$E_{F}$

$e_{h}$

$g$

$h$

$h_{\text {pri }}$

$h_{\text {sec }}$

$l_{1}, l_{2}, l_{3}, m_{1}, m_{2}, m_{3}, n_{1}, n_{2}, n_{3}$

$l_{c}$
Aspect ratio

Concentration factor relating the average strain in the effective reinforcement to that of the unknown effective material in which it is embedded

Width

Stiffness tensor of composites in the local coordinate system

Stiffness tensor of composites in the global coordinate system

Stiffness tensor of fibres

Stiffness tensor of matrix

Maximum deflection before failure

Elastic modulus of composite

Elastic modulus of fibre

Elastic modulus of the matrix

Flexural modulus

Hybrid effect

Normalised strength reduction factor

Depth

Thickness of primary fibre type section

Thickness of secondary fibre type section

Directional cosines

Critical fibre length 
$M_{x x}$

$P_{\max }$

$r_{h}$

S

$S_{f}$

$S_{m}$

$S_{T}$

$S_{F}$

$S_{F R o M}$

SRF

$S R F_{o}$

$S R F_{\infty}$

T

$\mathbf{T}_{\varepsilon}$

$V_{f}$

$V_{f p r i}$

$V_{f s e c}$

$\boldsymbol{\varepsilon}$

$\bar{\varepsilon}$

$\varepsilon_{F}$
Bending moment

Maximum load encountered before failure

Hybrid ratio

Eshelby's tensor

Strength of fibre

Strength of the matrix

Strength of short fibre composite

Flexural strength

Flexural strength from the rule of mixtures

Strength reduction factor

Strength reduction factor of the sphere composite

Strength reduction factor of the long fibre composite

Transformation matrix for stress

Transformation matrix for strain

Fibre volume fraction

Fibre volume fraction of primary fibre type section

Fibre volume fraction of secondary fibre type section

Strain tensor in the local coordinate system

Strain tensor in the global coordinate system

Flexural strain to failure 
$\phi, \theta, \beta$

$\boldsymbol{\sigma}$

$\overline{\boldsymbol{\sigma}}$

$\sigma_{F}$

$\tau_{i}$

$\varepsilon_{x x}^{0}$
Euler angles

Stress tensor in the local coordinate system

Stress tensor in the global coordinate system

Flexural stress

Interface shear strength

Mid-plane strain 


\section{Introduction}

Natural fibre reinforced composites have been widely studied. These composites have the advantages including light weight, low cost, abundance of raw materials, and excellent recyclability. More importantly, developing natural fibre composites provides a solution to the reuse of agricultural wastes. It is shown that natural fibre composites have a potential to replace glass fibre composites in many applications ${ }^{1}$.

A number of reviews on natural fibre reinforced biocomposites have been presented ${ }^{2-4}$. Overall, the properties of natural fibre reinforced composites are inferior to the synthetic fibre reinforced composites. Inspired by the success of synthetic fibre hybrid composites, research has been done to combine two or more types of natural fibres to form natural fibre reinforced composites.

Hybrid composites are materials made by combining two or more different types of fibres in a common matrix. They offer a range of properties that cannot be obtained with a single kind of reinforcement. Hybridization of two types of short fibres having different lengths and diameters can offer some advantages over using either of the fibres alone in a single polymer matrix. Hybrid composites have attracted the attention of many researchers as a way to enhance mechanical properties of composites ${ }^{5}$.

It was shown from the research on synthetic hybrid composites reinforced by glass and carbon fibres that positive hybrid effects and improved properties were found ${ }^{6-13}$. More recently, hybrid composites reinforced by natural/natural fibres are gaining increasing research interest ${ }^{5}$. Srinivasan et al. ${ }^{14}$ found that the flexural strength of banana/flax hybrid composite (F+B+GFRP) was higher than that of either the flax fibre composite (F+GFRP) or banana fibre composite (B+GFRP).

Boopalan et al. ${ }^{15}$ found a $4.3 \%$ increase in the flexural strength by partially replacing jute fibres by banana fibres. Alavudeen et al. ${ }^{16}$ found the flexural strength of the woven banana/kenaf fibre hybrid composite was superior to those of the individual fibres. Senthil Kumar et al. ${ }^{17}$ studied short banana and woven coconut sheath fibre hybrid polyester composites. It was shown that the hybrid layup 
with higher relative content of banana fibre yielded higher tensile and flexural strengths.

Venkateshwaran et al. ${ }^{18}$ studied the mechanical and water absorption behaviours of banana/sisal reinforced hybrid composites, and concluded that hybridisation of natural fibre composite by another natural fibre did not yield superior mechanical properties.

The research on natural fibre hybrid composites were mostly experimental based. Because natural fibres are derived from naturally grown plants, large variabilities exist with the physical, chemical and mechanical properties. Another important factor causing variabilities is the processing technique. It is seen hand layup has been the dominant processing technique, and this adds a significant amount of variability to the properties of composites.

It is seen in the literature that few modelling studies on natural fibre reinforced composites have been presented ${ }^{19}$. Modelling and simulation can provide an efficient tool for understanding the performance of composites. With the aid of simulation, it can be explained if the performance of natural fibre composites can be improved via hybridisation.

In this study, the flexural properties of short natural fibre reinforced hybrid composites were numerically studied by the Classical Beam Theory (CBT) and Finite Element Analysis (FEA), with the aim of finding if positive hybrid effects can be achieved.

\section{Material Models}

\subsection{Constituent Properties}

Five types of natural fibres: banana, flax, hemp, jute and sisal were chosen in this study. These five types of fibres were chosen because of their rich availability. The composites made using these five types of fibres have been widely studied ${ }^{14-18}$.

Flax (Linum usitatissimum) belongs to the bast fibres. It is grown in temperate regions and is one of the oldest fibre crops in the world. Flax is most frequently used in the higher value-added textile 
markets. Nowadays, it is widely used in the composites area. Jute is produced from plants of the genus Corchorus, which includes about 100 species. It is one of the cheapest natural fibres and is currently the bast fibre with the highest production volume. Kenaf belongs to the genus Hibiscus including about 300 species, and it shows good potential as a raw material for usage in composite products. Sisal (Agave sisalana) is a species of Agave and commercially produced in Brazil and East Africa $^{2}$. Banana fibre at present is a waste product of banana cultivation. Hence, without any additional cost input, banana fibre can be obtained for industrial purposes ${ }^{20}$.

In general, the strength of a fibre increases with increasing cellulose content and decreasing spiral angle with respect to the fibre axis. The cellulose content of banana and sisal fibres is almost same, but the spiral angle of the banana fibre (118) is much lower than that of the sisal fibre (208). Hence the inherent tensile properties of the banana fibre is higher than those of the sisal fibre. In addition, the diameter of the banana fibre is lower than that of the sisal fibre ${ }^{21}$. Hence the surface area of banana fibres in unit area of the composite is higher and the stress transfer is higher in the banana reinforced composite compared to that of the sisal reinforced composite.

Natural fibres are highly anisotropic ${ }^{21-23}$. Epoxy was chosen to be the matrix. The elastic moduli and CTE of the natural fibres and epoxy are shown in Table $1^{2,11,12,21-23}$. It is shown from Table 1 that flax fibre has the highest modulus, jute fibre has moderate modulus and banana, kenaf and sisal fibres have low moduli.

Table 1: Properties of fibres and epoxy

\begin{tabular}{ccccccc}
\hline & \multicolumn{5}{c}{ Fibre type } & \multirow{2}{*}{ Epoxy } \\
\cline { 2 - 5 } & Banana & Flax & Jute & Kenaf & Sisal & \\
\hline Elastic modulus $(\mathrm{GPa})$ & 29 & 59 & 39.4 & 20 & 28 & \multirow{2}{*}{3.1} \\
Longitudinal & 5.5 & 5.5 & 5.5 & 5.5 & 5.5 & \\
Transverse & 10 & 2.8 & -0.6 & 10 & 16.8 & \multirow{2}{*}{64} \\
Coefficient of thermal expansion $\left(10^{-6} \mathrm{~m} / \mathrm{m} /{ }^{\circ} \mathrm{C}\right)$ & & & & \\
$\quad$ Longitudinal & 72 & 79.8 & 77.2 & 72 & 70.8 & \\
$\quad$ Transverse & & & & & & \\
\hline
\end{tabular}




\subsection{Micromechanical Modelling}

Correct material properties are essential in the modelling of natural fibre reinforced hybrid composites. In this study, the elastic and thermoelastic properties of natural fibre composites were modelled using the method proposed by Taya et al. ${ }^{24,25}$ based on Eshelby's inclusion theory ${ }^{26}$ and Mori-Tanaka's mean field theory ${ }^{27}$. For a composite containing a single inclusion type, the effective stiffness according to the Mori-Tanaka method is given by

$$
\begin{aligned}
& \mathbf{C}=\left[\left(1-V_{f}\right) \mathbf{C}_{\mathbf{m}}+V_{f} \mathbf{C}_{\mathbf{f}} \mathbf{A} \llbracket\left(1-V_{f}\right) \mathbf{I}+V_{f} \mathbf{A}\right]^{-1} \\
& \mathbf{A}=\left[\mathbf{I}+\mathbf{S C}_{\mathbf{m}}^{-\mathbf{1}}\left(\mathbf{C}_{\mathbf{f}}-\mathbf{C}_{\mathbf{m}}\right)\right]^{-1}
\end{aligned}
$$

A fibre can be idealised to be a general ellipsoidal inclusion, as shown in Figure 1. The components of Eshelby's tensor $S_{i j k l}$ are dependent on the aspect ratio, which is defined to be $a=x_{3} / x_{1}=l / d$ for a fibre-like inclusion $\left(x_{1}=x_{2}<x_{3}\right)$.

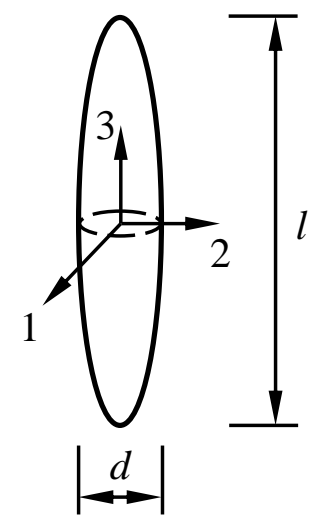

Figure 1: A fibre-like inclusion

When a composite material consisting of a matrix and multiple types of inclusions, the effective modulus is given by 


$$
\mathbf{C}=\left[\left(1-\sum_{i=1}^{n} V_{f i}\right) \mathbf{C}_{\mathbf{m}}+\sum_{i=1}^{n} V_{f i} \mathbf{C}_{\mathbf{f i}} \mathbf{A}_{\mathbf{i}}\right]\left[\left(1-\sum_{i=1}^{n} V_{f i}\right) \mathbf{I}+\sum_{i=1}^{n} V_{f i} \mathbf{A}_{\mathbf{i}}\right]^{-1}
$$

where $\mathbf{A}_{\mathbf{i}}(i=1 \ldots n)$ is given by

$$
\mathbf{A}_{\mathbf{i}}=\left[\mathbf{S}_{\mathbf{i}} \mathbf{C}_{\mathbf{m}}^{-1}\left(\mathbf{C}_{\mathrm{fi}}-\mathbf{C}_{\mathrm{m}}\right)+\mathbf{I}\right]^{-1}
$$

When a composite contains fibres of various aspect ratios and/or orientations. Each aspect ratio or orientation is treated as an inclusion type.

\subsection{Transformation}

When a fibre is oriented at an arbitrary angle, the effective stiffness need to be transformed from the fibre coordinate system $o x^{\prime} y^{\prime}$ to the global coordinate system $o x y$, as shown in Figure 2. This can be conveniently done using Euler angles, $\phi, \theta$ and $\beta$, which are referred to respectively as precession, nutation and spin, as shown in Figure 3. For unidirectional composites, $\phi=\theta=\beta=0$; for 2-D random composites, $\phi=\beta=0$ and $0 \leq \theta \leq \pi$; and for 3 -D random composites, $\beta=0,0 \leq \theta \leq \pi$ and $0 \leq \phi \leq 2 \pi$.

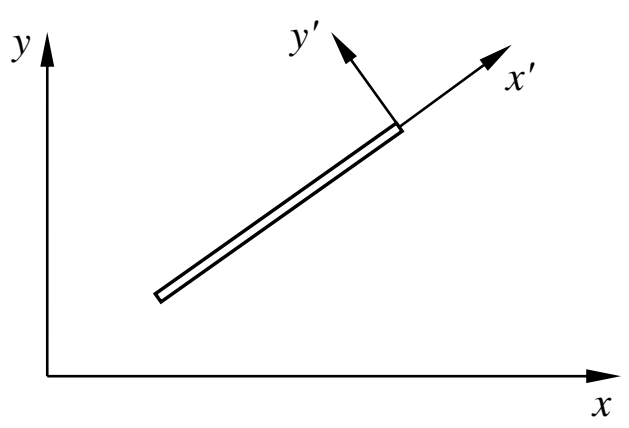

Figure 2: Transformation between coordinate systems 


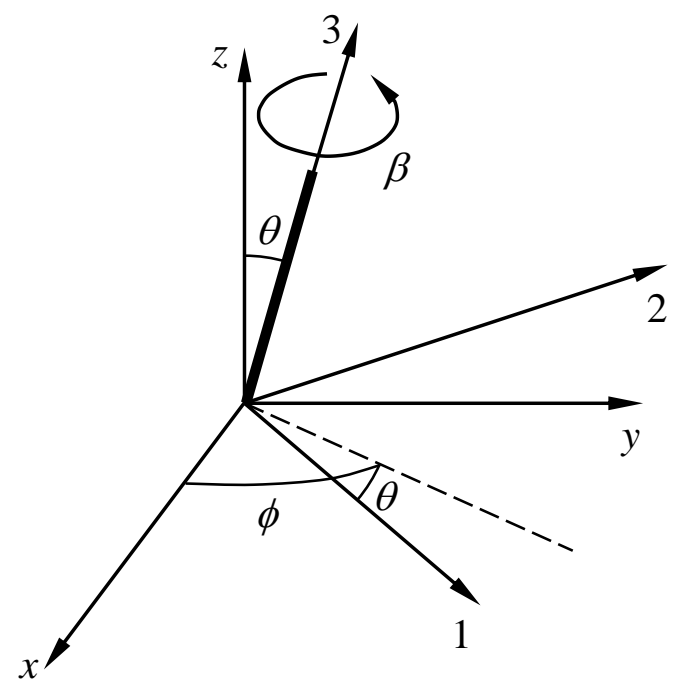

Figure 3: Euler angles

The transformation matrix for stress tensors is given by

$$
\mathbf{T}=\left[\begin{array}{cccccc}
l_{1}^{2} & m_{1}^{2} & n_{1}^{2} & 2 m_{1} n_{1} & 2 l_{1} n_{1} & 2 l_{1} m_{1} \\
l_{2}^{2} & m_{2}^{2} & n_{2}^{2} & 2 m_{2} n_{2} & 2 l_{2} n_{2} & 2 l_{2} m_{2} \\
l_{3}^{2} & m_{3}^{2} & n_{3}^{2} & 2 m_{3} n_{3} & 2 l_{3} n_{3} & 2 l_{3} m_{3} \\
l_{2} l_{3} & m_{2} m_{3} & n_{2} n_{3} & m_{2} n_{3}+m_{3} n_{2} & l_{2} n_{3}+l_{3} n_{2} & l_{2} m_{3}+l_{3} m_{2} \\
l_{1} l_{3} & m_{1} m_{3} & n_{1} n_{3} & m_{1} n_{3}+m_{3} n_{1} & l_{1} n_{3}+l_{3} n_{1} & l_{1} m_{3}+l_{3} m_{1} \\
l_{1} l_{2} & m_{1} m_{2} & n_{1} n_{2} & m_{1} n_{2}+m_{2} n_{1} & l_{1} n_{2}+l_{2} n_{1} & l_{1} m_{2}+l_{2} m_{1}
\end{array}\right]
$$

where

$$
\begin{array}{lll}
l_{1}=\cos \phi \cos \theta & m_{1}=\sin \phi \cos \theta & n_{1}=-\sin \theta \\
l_{2}=-\sin \phi & m_{2}=\cos \phi & n_{2}=0 \\
l_{3}=\cos \phi \sin \theta & m_{3}=\sin \phi \sin \theta & n_{3}=\cos \theta
\end{array}
$$

The transformation of stress tensors is given by

$$
\boldsymbol{\sigma}=\mathbf{T} \overline{\boldsymbol{\sigma}}
$$

The transformation of strain vectors is given by

$$
\varepsilon=\mathbf{T}^{\mathrm{T}} \overline{\boldsymbol{\varepsilon}}
$$

Therefore, the stiffness tensor in the global coordinate system is given by 


$$
\overline{\mathbf{C}}=\mathbf{T}^{-\mathbf{1}} \mathbf{C}\left(\mathbf{T}^{-1}\right)^{\mathbf{T}}
$$

The Eshelby's tensor needs also to be transformed in such way that

$$
\overline{\mathbf{S}}=\mathbf{T}^{\mathrm{T}} \mathbf{S T}
$$

where $\overline{\mathbf{S}}=\mathbf{T}^{\mathrm{T}} \mathbf{S T}$ is the transformed Eshelby's tensor.

\subsection{Aspect Ratio}

The distribution of fibre aspect ratios was characterised by a Weibull distribution as shown in Figure

4, following experimental observations by Le Moigne et al. ${ }^{28}$ and El-Shekeil ${ }^{29}$.

Figure 4: Distribution of aspect ratios

\subsection{Elastic Properties}

The compliance tensor is the inverse of the stiffness tensor, i.e. $\overline{\mathbf{S}}_{\mathrm{C}}=\overline{\mathbf{C}}^{-\mathbf{1}}$. From the compliance tensor, the elastic moduli, Poisson's ratios and shear moduli can be derived as follows.

$$
\begin{aligned}
& E_{L}=1 / \bar{S}_{C 33} \\
& E_{T}=1 / \bar{S}_{C 11} \\
& E_{Z}=1 / \bar{S}_{C 22} \\
& v_{T Z}=-\bar{S}_{C 21} / \bar{S}_{C 11} \\
& v_{Z L}=-\bar{S}_{C 32} / \bar{S}_{C 22} \\
& v_{L T}=-\bar{S}_{C 13} / \bar{S}_{C 33} \\
& G_{T Z}=1 / \bar{S}_{C 66}
\end{aligned}
$$




$$
\begin{gathered}
G_{Z L}=1 / \bar{S}_{C 44} \\
G_{L T}=1 / \bar{S}_{C 55}
\end{gathered}
$$

These properties will be the input to FEA.

\subsection{Strength}

For a short fibre composite, its tensile strength is given by ${ }^{30}$

$$
S_{T}=S R F \cdot S_{f} \cdot V_{f}
$$

where $S R F$ is the strength reduction factor, given by

$$
S R F=S R F_{o}+g\left(S R F_{\infty}-S R F_{o}\right)
$$

$S R F_{o}$ and $S R F_{\infty}$ are given by

$$
\begin{aligned}
& S R F_{o}=\frac{S_{m} E_{c}\left(1-V_{f}\right)^{\frac{1}{3}}}{S_{f} V_{f} E_{m}} \\
& S R F_{\infty}=0.5+\left(\frac{E_{f}}{E_{m}}\right)^{-0.87}
\end{aligned}
$$

The normalised strength reduction factor $g$ is given by

$$
g=1-0.97 \exp (-0.42 \beta)
$$

where $\beta=\frac{a \tau_{i}}{S_{f}}$ and $\tau_{i}$ is the interface shear strength, given by

$$
\tau_{i}=\frac{S_{f} d_{f}}{2 l_{c}}
$$


This model was used to model the strength of short flax fibre/epoxy composite. The normalised strength vs. fibre volume fraction is shown in Figure 5. It is shown that the predicted composite strength is very close to the epoxy strength, and Baiardo et al. ${ }^{31}$ experimentally showed that the flax composite had a similar tensile strength to the resin. Thus, in this study, the tensile strength of natural fibre composites was taken to be the same as the epoxy strength. The compressive strength is usually higher ${ }^{32}$ than the tensile strength. Thus, failure under three point bend test usually occurs at the tensile face.

Figure 5: Normalised tensile strength of short flax fibre/epoxy composite 


\section{Modelling of Hybrid Composites}

\subsection{Stacking Configuration and Hybrid Ratio}

A simple hybrid composite consists of two fibre types subjected to three point bending is shown in

Figure 6. The two fibre types are denoted primary and secondary, respectively. It is seen the primary and secondary fibre types are on the tensile and compressive faces, respectively.

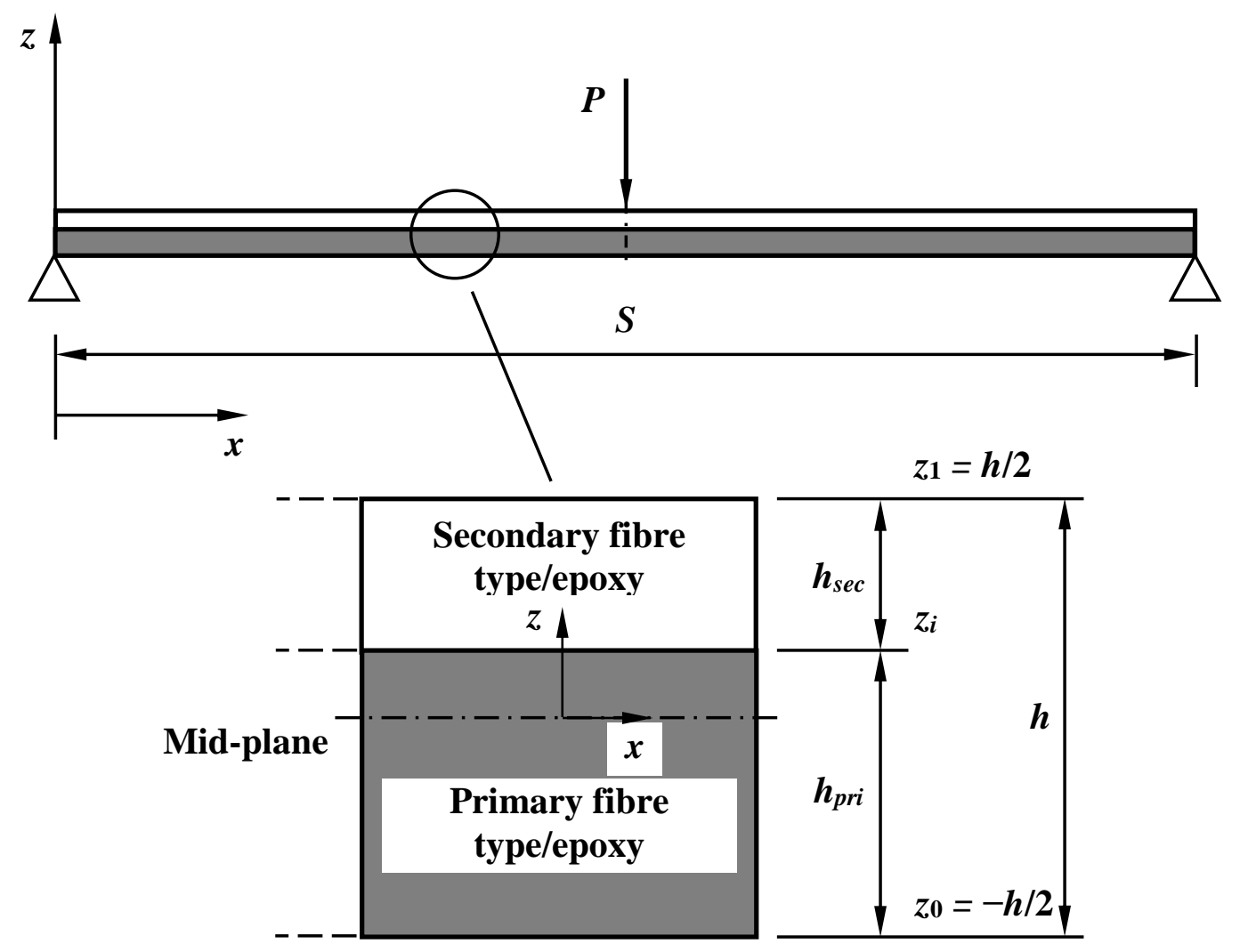

Figure 6: A hybrid composite specimen in the three point bend test

For the purpose of quantitatively characterising the degree of hybridisation, the hybrid ratio is introduced, which is defined to be the volume fraction of fibres of the secondary type in all fibres, i.e.

$$
r_{h}=\frac{h_{s e c} V_{f s e c}}{h_{p r i} V_{f p r i}+h_{s e c} V_{f s e c}}
$$


A hybrid sandwich composite consists of two fibre types subjected to three point bending is shown in

Figure 7. It is seen the primary fibre type is the core and the secondary fibre type is the skin.

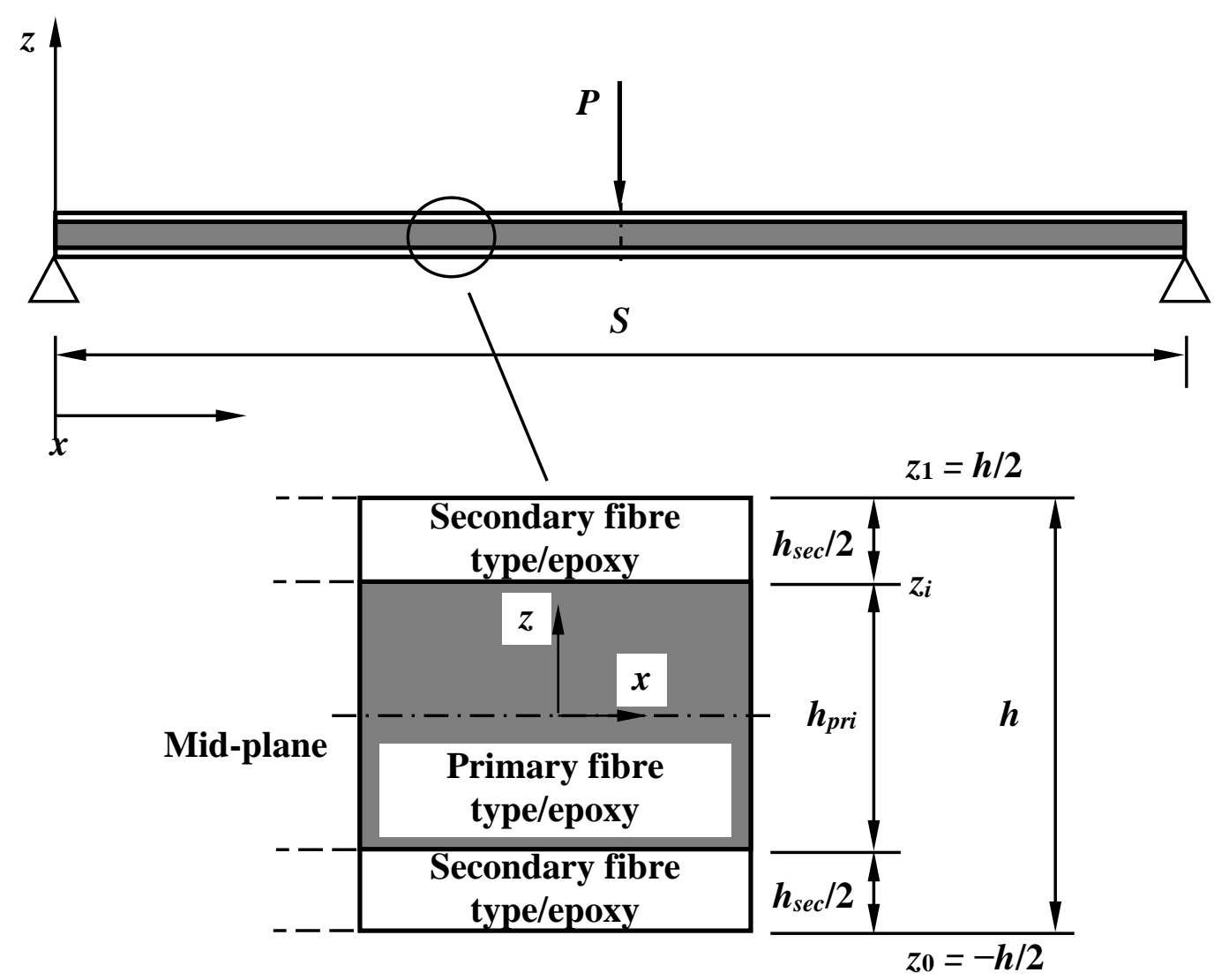

Figure 7: A hybrid sandwich composite specimen in the three point bend test 
An alternative hybrid sandwich composite consists of two fibre types subjected to three point bending is shown in Figure 8. It is seen the primary fibre type is the skin and the secondary fibre type is the core.

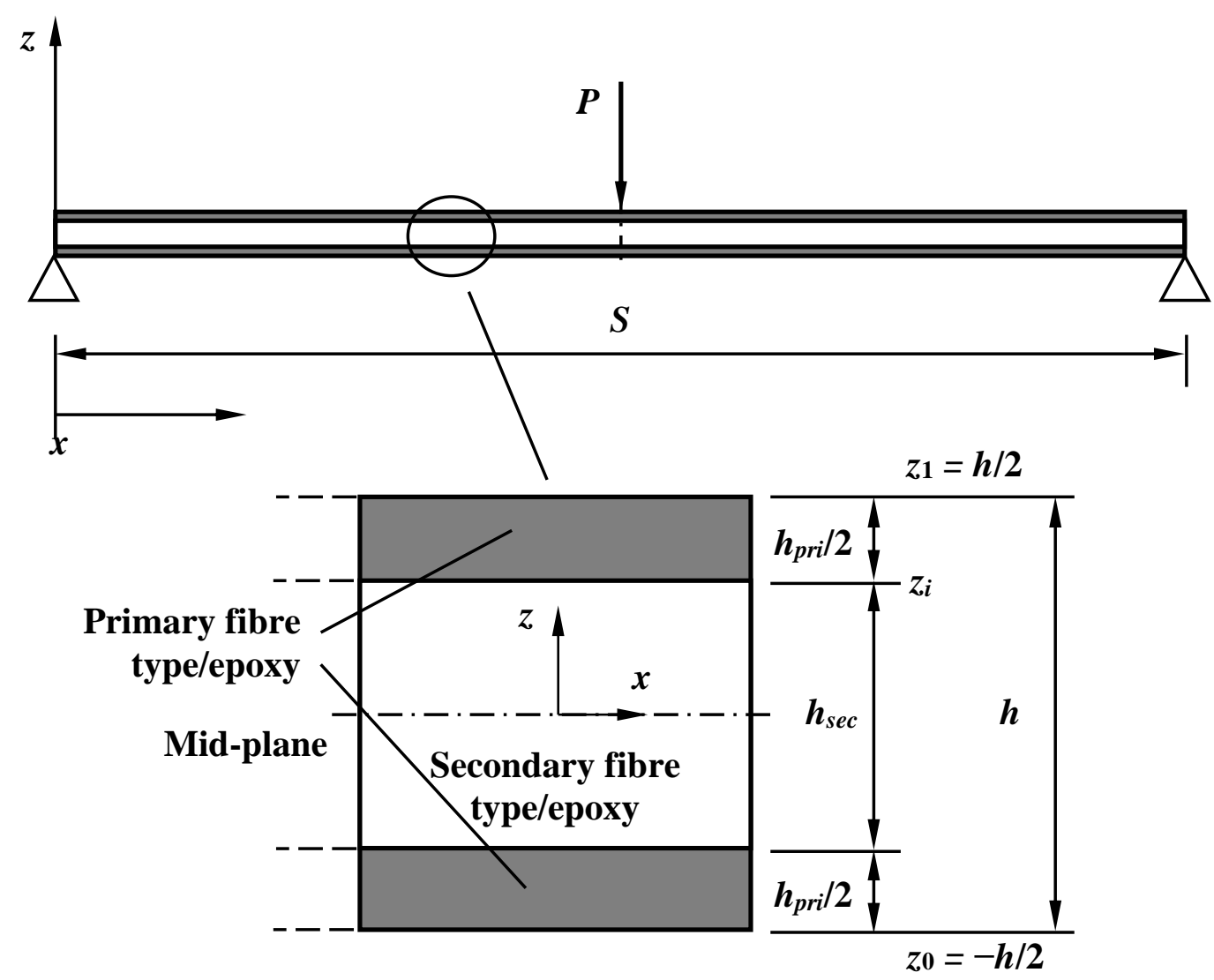

Figure 8: An alternative hybrid sandwich composite specimen in the three point bend test

\subsection{Flexural Properties}

According to procedure A of ASTM D7264/D7264M-15, for a specimen in three point bend test, the flexural strength $\left(S_{F}\right)$, strain to failure $\left(\varepsilon_{F}\right)$ and modulus $\left(E_{F}\right)$ are given by ${ }^{33}$ :

$$
\begin{gathered}
S_{F}=\frac{3 P_{\max } L}{2 b h^{2}} \\
\varepsilon_{F}=\frac{6 D h}{L^{2}}
\end{gathered}
$$




$$
E_{F}=\frac{\Delta \sigma_{F}}{\Delta \varepsilon_{F}}
$$

\subsection{Classical Beam Theory}

For the hybrid composite in three point bend test, the constitutive equation according to the $\mathrm{CBT}^{34}$ is

$$
\left\{\begin{array}{c}
0 \\
M_{x x}
\end{array}\right\}=\left[\begin{array}{ll}
A_{11} & B_{11} \\
B_{11} & D_{11}
\end{array}\right]\left\{\begin{array}{l}
\varepsilon_{x x}^{0} \\
\kappa_{x x}
\end{array}\right\}
$$

where the moment $M_{x x}$ is negative.

For the hybrid composite as shown in Figure 6, the mid-plane strain and curvature are

$$
\begin{gathered}
\varepsilon_{x x}^{0}=\frac{6\left(E_{11 p r i}-E_{11 s e c}\right) h_{p r i} h_{s e c} M_{x x}}{\left(E_{11 p r i} h_{p r i}^{2}-E_{11 s e c} h_{s e c}^{2}\right)^{2}+4 E_{11 p r i} E_{11 s e c} h_{p r i} h_{s e c}\left(h_{p r i}+h_{s e c}\right)^{2}} \\
\kappa_{x x}=\frac{12\left(E_{11 p r i} h_{p r i}+E_{11 s e c} h_{s e c}\right) M_{x x}}{\left(E_{11 p r i} h_{p r i}^{2}-E_{11 s e c} h_{s e c}^{2}\right)^{2}+4 E_{11 p r i} E_{11 s e c} h_{p r i} h_{s e c}\left(h_{p r i}+h_{s e c}\right)^{2}}
\end{gathered}
$$

Since failure occurs at the tensile face of a test specimen, only the lower faces of the primary and secondary fibre type section need to be examined.

The tensile stress at the lower face of the primary fibre type/epoxy section is

$$
\sigma_{x x p r i \_l}=-\frac{6\left(E_{11 p r i}^{2} h_{p r i}^{2}+2 E_{11 p r i} E_{11 s e c} h_{p r i} h_{s e c}+E_{11 p r i} E_{11 s e c} h_{s e c}^{2}\right) M_{x x}}{\left(E_{11 p r i} h_{p r i}^{2}-E_{11 s e c} h_{s e c}^{2}\right)^{2}+4 E_{11 p r i} E_{11 s e c} h_{p r i} h_{s e c}\left(h_{p r i}+h_{s e c}\right)^{2}}
$$

The stress at the lower face of the secondary fibre type/epoxy section is

$$
\sigma_{x x s e c \_l}=\frac{6\left(E_{11 p r i} E_{11 \text { sec }} h_{p r i}^{2}-E_{11 s e c}^{2} h_{s e c}^{2}\right) M_{x x}}{\left(E_{11 p r i} h_{p r i}^{2}-E_{11 s e c} h_{s e c}^{2}\right)^{2}+4 E_{11 p r i} E_{11 s e c} h_{p r i} h_{s e c}\left(h_{p r i}+h_{s e c}\right)^{2}}
$$

Since $S_{T p r i}=S_{T s e c}=S_{m}$, the failure moment at the primary fibre type section is given by 


$$
M_{x x \max \_p r i}=-\frac{S_{m}\left[\left(E_{11 p r i} h_{p r i}^{2}-E_{11 s e c} h_{s e c}^{2}\right)^{2}+4 E_{11 p r i} E_{11 s e c} h_{p r i} h_{s e c}\left(h_{p r i}+h_{s e c}\right)^{2}\right]}{6\left(E_{11 p r i}^{2} h_{p r i}^{2}+2 E_{11 p r i} E_{11 \text { sec }} h_{p r i} h_{s e c}+E_{11 p r i} E_{11 s e c} h_{s e c}^{2}\right)}
$$

The failure moment at the secondary fibre type section is given by

$$
M_{x x \text { max } \_ \text {sec }}=\frac{S_{m}\left[\left(E_{11 p r i} h_{p r i}^{2}-E_{11 \text { sec }} h_{s e c}^{2}\right)^{2}+4 E_{11 p r i} E_{11 \text { sec }} h_{p r i} h_{s e c}\left(h_{p r i}+h_{s e c}\right)^{2}\right]}{6\left(E_{11 p r i} E_{11 s e c} h_{p r i}^{2}-E_{11 s e c}^{2} h_{s e c}^{2}\right)}
$$

If $M_{x x \max _{-} p r i}<M_{x x \max _{-} s e c}$ or $\sigma_{x x p r i \_l}>\sigma_{x x s e e_{-} l}$, failure occurs in the primary fibre type/epoxy section, and if $M_{x x \text { max }_{-} p r i}>M_{x x \max _{-} s e c}$ or $\sigma_{x x p r i \_l}<\sigma_{x x s e c_{-} l}$, failure occurs in the secondary fibre type/epoxy section, i.e.

$$
M_{x x \max }= \begin{cases}-\frac{S_{m}\left[\left(E_{11 p r i} h_{p r i}^{2}-E_{11 s e c} h_{s e c}^{2}\right)^{2}+4 E_{11 p r i} E_{11 s e c} h_{p r i} h_{s e c}\left(h_{p r i}+h_{s e c}\right)^{2}\right]}{6\left(E_{11 p r i}^{2} h_{p r i}^{2}+2 E_{11 p r i} E_{11 s e c} h_{p r i} h_{s e c}+E_{11 p r i} E_{11 s e c} h_{s e c}^{2}\right)} & h_{\text {sec }} \leq h_{\text {sec_crit }} \\ \frac{S_{m}\left[\left(E_{11 p r i} h_{p r i}^{2}-E_{11 s e c} h_{s e c}^{2}\right)^{2}+4 E_{11 p r i} E_{11 s e c} h_{p r i} h_{s e c}\left(h_{p r i}+h_{s e c}\right)^{2}\right]}{6\left(E_{11 p r i} E_{11 s e c} h_{p r i}^{2}-E_{11 s e c}^{2} h_{s e c}^{2}\right)} & h_{\text {sec }} \geq h_{\text {sec_crit }}\end{cases}
$$

The maximum flexural strength occurs when $M_{x x \max _{-} p r i}=M_{x x \max \_s e c_{1}}$ or $\sigma_{x x p r i \_l}=\sigma_{x x s e c_{-} l}$, i.e.

$$
\frac{h_{p r i}}{h_{s e c}}=\frac{-1+\sqrt{1-\frac{\left(E_{11 p r i}^{2}-E_{11 s e c}^{2}\right)}{E_{11 p r i} E_{11 s e c}}}}{1+\frac{E_{11 p r i}}{E_{11 s e c}}}
$$

For the hybrid sandwich composite as shown in Figure 7, the failure moment at the primary fibre type section is given by

$$
M_{x x \max _{-} p r i}=-\frac{S_{m}\left[E_{11 p r i} h_{p r i}^{3}+E_{11 s e c} h_{s e c}\left(3 h_{p r i}^{2}+3 h_{p r i} h_{s e c}+h_{s e c}^{2}\right)\right]}{6 E_{11 p r i} h_{p r i}}
$$

The failure moment at the secondary fibre type section is given by 


$$
M_{x x \text { max_sec }}=\frac{S_{m}\left[E_{11 p r i} h_{p r i}^{3}+E_{11 s e c} h_{s e c}\left(3 h_{p r i}^{2}+3 h_{p r i} h_{s e c}+h_{s e c}^{2}\right)\right]}{6 E_{11 s e c} h}
$$

If $M_{x x \max _{-} p r i}<M_{x x \max _{-} s e c}$ or $\sigma_{x x p r i \_l}>\sigma_{x x s e e_{-} l}$, failure occurs in the primary fibre type/epoxy section, and if $M_{x x \text { max }_{-} p r i}>M_{x x \text { max } \_s e c_{1}}$ or $\sigma_{x x p r i \_l}<\sigma_{x x s e c_{-} l}$, failure occurs in the secondary fibre type/epoxy section, i.e.

$$
M_{x x \max }= \begin{cases}-\frac{S_{m}\left[E_{11 p r i} h_{p r i}^{3}+E_{11 s e c} h_{s e c}\left(3 h_{p r i}^{2}+3 h_{p r i} h_{s e c}+h_{s e c}^{2}\right)\right]}{6 E_{11 p r i} h_{p r i}} & h_{s e c} \leq h_{\text {sec_crit }} \\ \frac{S_{m}\left[E_{11 p r i} h_{p r i}^{3}+E_{11 s e c} h_{s e c}\left(3 h_{p r i}^{2}+3 h_{p r i} h_{s e c}+h_{s e c}^{2}\right)\right]}{6 E_{11 s e c} h} & h_{s e c} \geq h_{s e c_{-} c r i t}\end{cases}
$$

The maximum flexural strength occurs when $M_{x x \max _{-} p r i}=M_{x x \max _{-} \text {sec }}$ or $\sigma_{x x p r i \_l}=\sigma_{x x s e c_{-} l}$, i.e.

$$
\frac{h_{p r i}}{h}=\frac{E_{11 s e c}}{E_{11 p r i}}
$$

or

$$
\frac{h_{s e c}}{h}=1-\frac{E_{11 s e c}}{E_{11 p r i}}
$$

It is seen from Eqn. 33 that a feasible solution is obtained when $E_{11 s e c}<E_{11 p r i}$.

For the hybrid sandwich composite as shown in Figure 8, the failure moment at the primary fibre type section is given by

$$
M_{x x \max _{-} p r i}=-\frac{S_{m}\left[E_{11 p r i} h_{p r i}\left(h_{p r i}^{2}+3 h_{p r i} h_{s e c}+3 h_{s e c}^{2}\right)+E_{11 s e c} h_{s e c}^{3}\right]}{6 E_{11 p r i} h}
$$

The failure moment at the secondary fibre type section is given by

$$
M_{x x \text { max_sec }}=\frac{S_{m}\left[E_{11 p r i} h_{p r i}\left(h_{p r i}^{2}+3 h_{p r i} h_{s e c}+3 h_{s e c}^{2}\right)+E_{11 s e c} h_{s e c}^{3}\right]}{6 E_{11 s e c} h_{s e c}}
$$


If $M_{x x \text { max } \_p r i_{1}}<M_{x x \max _{-} \text {sec }}$ or $\sigma_{x x p r i \_l}>\sigma_{x x s e e_{-} l}$, failure occurs in the primary fibre type/epoxy section, and if $M_{x x \text { max }_{-} p r i}>M_{x x \text { max } \_s e c_{1}}$ or $\sigma_{x x p r i \_l}<\sigma_{x x s e c_{-} l}$, failure occurs in the secondary fibre type/epoxy section, i.e.

$$
M_{x x \max }= \begin{cases}-\frac{S_{m}\left[E_{11 p r i} h_{p r i}\left(h_{p r i}^{2}+3 h_{p r i} h_{s e c}+3 h_{s e c}^{2}\right)+E_{11 s e c} h_{s e c}^{3}\right]}{6 E_{11 p r i} h} & h_{s e c} \leq h_{s e c_{-} c r i t} \\ \frac{S_{m}\left[E_{11 p r i} h_{p r i}\left(h_{p r i}^{2}+3 h_{p r i} h_{s e c}+3 h_{s e c}^{2}\right)+E_{11 s e c} h_{s e c}^{3}\right]}{6 E_{11 s e c} h_{s e c}} & h_{s e c} \geq h_{s e c_{-} c r i t}\end{cases}
$$

The maximum flexural strength occurs when $M_{x x \max _{-} p r i}=M_{x x \max _{-} s e c}$ or $\sigma_{x x p r i_{-} l}=\sigma_{x x s e c_{-} l}$, i.e.

$$
\frac{h_{s e c}}{h}=\frac{E_{11 p r i}}{E_{11 s e c}}
$$

or

$$
\frac{h_{p r i}}{h}=1-\frac{E_{11 p r i}}{E_{11 s e c}}
$$

It is seen from Eqn. 37 that a feasible solution is obtained when $E_{11 s e c}>E_{11 p r i}$.

Because the stress distribution is uniform in compression but non-uniform in bending, from Weibull statistical theory, the flexural strength is about $30 \%$ to $50 \%$ higher than the tensile strength ${ }^{35}$. Thus, in this study, the maximum bending load was increased by $30 \%$ and the flexural strength is given by:

$$
S_{F}=-\frac{1.3 \cdot 3\left(\frac{4 M_{x x \max }}{S}\right) S}{2 h^{2}}=-\frac{7.8 M_{x x \max }}{h^{2}}
$$

\subsection{Finite Element Analysis}

In addition to the CBT, FEA was also employed in this study to model the natural fibre hybrid composites in three point bend. The FEA based model was widely used in previous research on 
synthetic fibre reinforced hybrid composites ${ }^{6-13}$. In this study, a commercial software ANSYS was used. The hybrid composite was modelled as a solid simply supported beam and a bending load was applied at the mid-span. The flexural modulus was obtained from the bending load and corresponding mid-span displacement using Eqn. 20. For the flexural strength, the bending load was increased until any stress reached the corresponding strength. This maximum bending load was increased by $30 \%$ and the flexural strength was calculated using Eqn. 18.

\subsection{Hybrid Effect}

The flexural strength of the hybrid composites according to the RoM is given by

$$
S_{F R o M}=S_{F p r i}\left(1-r_{h}\right)+S_{F s e c} r_{h}
$$

The hybrid effect is the deviation from the RoM, i.e.

$$
e_{h}=\frac{S_{F}}{S_{F R o M}}-1
$$

\subsection{Model Validation}

For the purpose of validating the developed modelling approach, the hybrid composites reinforced with banana, sisal and glass fibres from ${ }^{36}$ were simulated using the developed model. The composite specimens were made by compression moulding on a DARRAGON hydraulic compression machine of 100 ton capacity. The stacking sequences and corresponding fibre volume fractions are shown in Table 2.

The flexural moduli and strengths from the experiments and FEA are shown in Figure 9. It is shown that the model can accurately predict the general trends of the flexural modulus and strength. However, the FEA predictions are higher than the experimental values. 
Table 2: Stacking sequences and fibre volume fractions of hybrid composites reinforced with banana, sisal and glass fibres

\begin{tabular}{lccc}
\hline \multirow{2}{*}{ Stacking sequence } & \multicolumn{3}{c}{ Fibre volume fraction } \\
Banana & Sisal & Glass \\
\hline $\mathrm{B}$ & 0.31 & - & - \\
$\mathrm{G} / \mathrm{B} / \mathrm{G}$ & 0.2 & - & 0.08 \\
$\mathrm{G} / \mathrm{B} / \mathrm{G} / \mathrm{B} / \mathrm{G}$ & 0.16 & - & 0.14 \\
$\mathrm{~S}$ & - & 0.29 & - \\
$\mathrm{G} / \mathrm{S} / \mathrm{G}$ & - & 0.21 & 0.09 \\
$\mathrm{G} / \mathrm{S} / \mathrm{G} / \mathrm{S} / \mathrm{G}$ & - & 0.15 & 0.13 \\
$\mathrm{BS}$ & 0.16 & 0.15 & - \\
$\mathrm{G} / \mathrm{BS} / \mathrm{G}$ & 0.12 & 0.11 & 0.08 \\
G/BS/G/BS/G & 0.07 & 0.06 & 0.14 \\
\hline
\end{tabular}

Figure 9: Flexural moduli (left) and strengths (right) from the experiments and FEA for the hybrid composites reinforced with banana, sisal and glass fibres

The model was also used to model the flexural strengths of continuous unidirectional Palmyra palm leaf stalk fibre/glass-polyester composites ${ }^{37}$. The composite specimens were made by compression moulding by applying a force of 2 tons by hydraulic compression. The flexural strengths from the experiments and FEA are shown in Figure 10. The hybrid ratio is defined to be the volume fraction of glass fibres in all fibres. Good agreement between the experimental and predicted flexural strengths is found. The FEA predictions are $8 \%-22 \%$ higher than the experimental results.

Figure 10: Flexural strengths from the experiments and FEA for the continuous unidirectional Palmyra palm leaf stalk fibre/glass-polyester composites

The model was also used to model the flexural moduli and strengths of continuous unidirectional Palmyra palm leaf stalk fibre/jute-polyester composites ${ }^{38}$. The composite specimens were made by compression moulding by applying a force of 2 tons by hydraulic compression. The flexural moduli and strengths from the experiments and FEA are shown in Figure 11. The hybrid ratio is defined to be the volume fraction of jute fibres in all fibres. Good agreement between the experimental and 
predicted flexural moduli and strengths is found. The differences between the FEA predictions and experimental results are within $5 \%$ for the flexural modulus. For the flexural strength, the experimental results are $20 \%$ and $25 \%$ higher than the FEA predictions when the hybrid ratios are 0.5 and 0.75 , respectively. At other hybrid ratios, the differences between the FEA predictions and experimental results are within $7 \%$.

Figure 11: Flexural moduli (left) and strengths (right) from the experiments and FEA for the continuous unidirectional Palmyra palm leaf stalk fibre/jute-polyester composites

\subsection{Model Application}

All composite laminates consist of 8 laminas of $0.25 \mathrm{~mm}$ thickness. First, the primary fibre type laminas were replaced by secondary fibre type laminas layer-by-layer from the compressive to the tensile faces, as shown in Figure 12. Secondly, two sandwich type substitutions: outer-to-inner (Figure 13) and inner-to-outer (Figure 14) substitutions were studied.

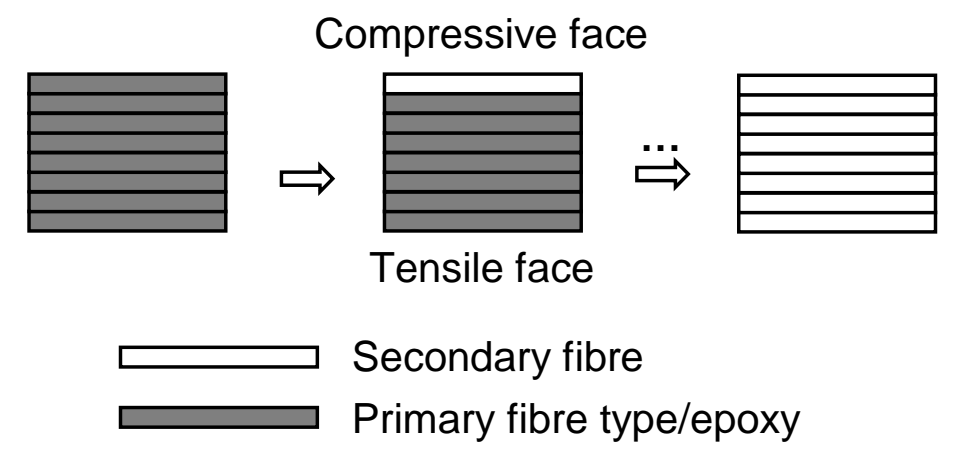

Figure 12: Sequential substitution of secondary fibre type laminas for primary type laminas 


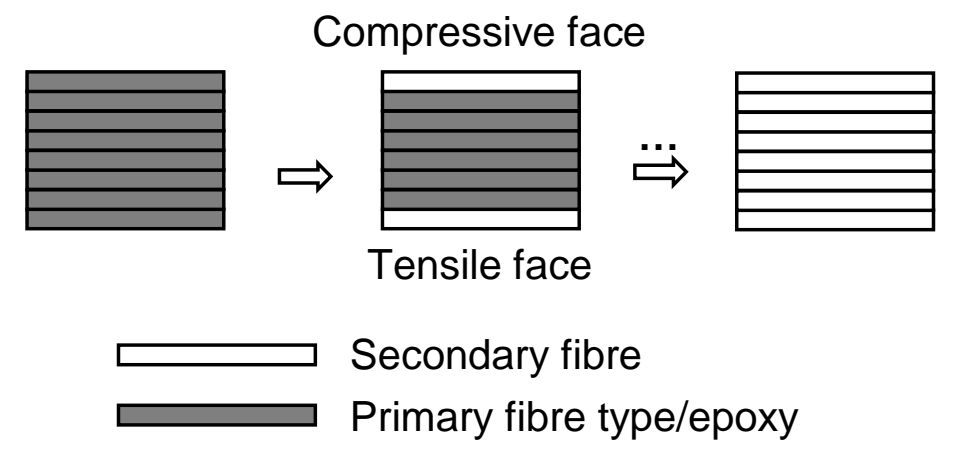

Figure 13: Outer-to-inner substitution of secondary fibre type laminas for primary type laminas

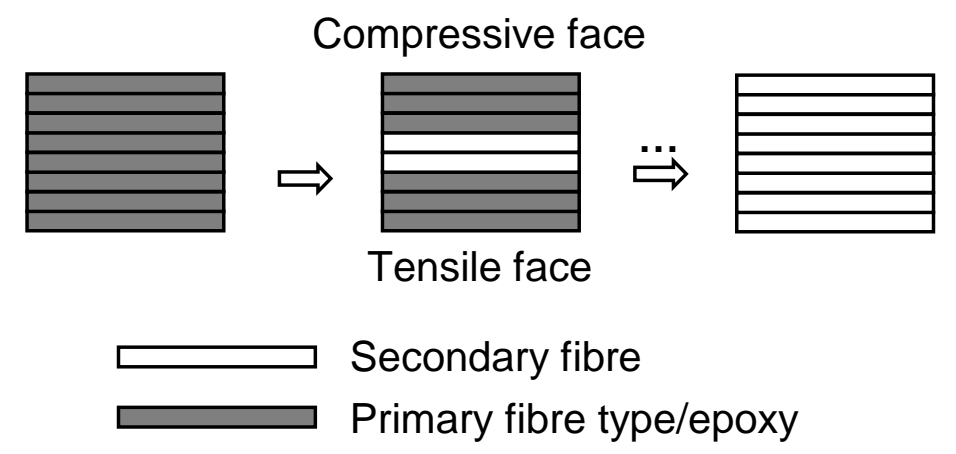

Figure 14: Inner-to-outer substitution of secondary fibre type laminas for primary type laminas

\section{Results and Discussion}

\subsection{Sequential Substitution}

When the primary and secondary fibre types are sisal and flax, respectively, the condition in Eqn. 31 is met when both fibre volume fractions are $30 \%$. The flexural strength vs. hybrid ratio is shown in Figure 15, from which it is seen that the predictions from the CBT and FEA are in good agreement and the maximum flexural strength occurs when the hybrid ratio is 0.875 , i.e. the stacking sequence is $\left[\mathrm{F}_{7} \mathrm{~S}\right]$.

Figure 15: Normalised flexural strength vs. hybrid ratio of sisal/flax hybrid composites with $V_{f p r i}=V_{f s e c}=30 \%$ 
The maximum flexural strength and corresponding hybrid ratio are shown in Figure 16. It is shown that the maximum flexural strength occurs when the primary and secondary fibre volume fractions are $30 \%$ and $70 \%$, respectively, and the corresponding hybrid ratio is 0.82 . The flexural strength is $35 \%$ higher than the flexural strength of single natural fibre type composites.

Figure 16: Maximum normalised flexural strength (left) and corresponding hybrid ratio (right) of sisal/flax hybrid composites

When the primary and secondary fibre types are flax and sisal, respectively, and both fibre volume fractions are $30 \%$, the flexural strength vs. hybrid ratio is shown in Figure 17, from which it is seen that flexural strength is lower than the flexural strength of single fibre type composites.

Figure 17: Normalised flexural strength vs. hybrid ratio of flax/sisal hybrid composites with $V_{f p r i}=V_{f s e c}=30 \%$

A general rule is that one lamina of higher stiffness should be placed on the tensile face of a hybrid composite in order to obtain improved flexural strength.

When sisal and banana fibres are the primary and secondary fibre types, respectively, the normalised flexural strength for the sequential substitution from the compressive to tensile faces is shown in Figure 18. It is shown that little change is shown in the flexural strength with the substitution of secondary fibre types. This is in agreement with a previous study ${ }^{18}$.

Figure 18: Normalised flexural strength vs. hybrid ratio of sisal/banana hybrid composites with $V_{f p r i}=V_{f s e c}=30 \%$ 


\subsection{Outer-to-Inner Substitution}

When the primary and secondary fibre types are sisal and flax, respectively, it is seen from Eqn. 33 that a feasible solution cannot be obtained since $E_{11 \text { sec }}>E_{11 p r i}$. The flexural strength cannot be improved via hybridisation. The flexural strength vs. hybrid ratio is shown in Figure 19, from which it is seen that the predictions from the CBT and FEA are in good agreement.

Figure 19: Normalised flexural strength vs. hybrid ratio of sisal/flax hybrid sandwich composites with $V_{f p r i}=V_{f s e c}$ $=30 \%$ (outer-inner substitution)

\subsection{Inner-to-Outer Substitution}

When the primary and secondary fibre types are sisal and flax, respectively, it is seen that the condition in Eqn. 37 is met since $E_{11 s e c}>E_{11 p r i}$. The flexural strength can be improved via hybridisation. The flexural strength vs. hybrid ratio is shown in Figure 20, from which it is seen that the predictions from the CBT and FEA are in good agreement. The flexural strength reaches the maximum when the hybrid ratio is 0.775 , and the improvement is $13.5 \%$ compared to the single natural fibre type composites.

Figure 20: Normalised flexural strength vs. hybrid ratio of sisal/flax hybrid sandwich composites with $V_{f p r i}=V_{f s e c}$ $=30 \%$ (inner-outer substitution)

\section{Conclusions}

The hybrid composites reinforced by two types of short natural fibres were modelled by the CBT and FEA. The models were validated against the experimental data in the literature. Both asymmetric and sandwich hybrid composites were studied. From the results, the following conclusions can be drawn: 
1. A general rule is that one lamina of higher stiffness should be placed on the tensile face of a hybrid composite in order to obtain improved flexural strength. An example is the sisal/flax hybrid composite. The maximum flexural strength occurs when the hybrid ratio is 0.875 , i.e. the stacking sequence is $\left[\mathrm{F}_{7} \mathrm{~S}\right]$. It is shown that the maximum flexural strength occurs when the primary and secondary fibre volume fractions are $30 \%$ and $70 \%$, respectively, and the corresponding hybrid ratio is 0.82 . The flexural strength is $35 \%$ higher than the flexural strength of single natural fibre type composites.

2. For the sandwich type hybrid composites, the higher stiffness material should be placed in the core and the lower stiffness material should be the skin. When the primary and secondary fibre types are sisal and flax, respectively, the flexural strength reaches the maximum when the hybrid ratio is 0.775 , and the improvement is $13.5 \%$ compared to the single natural fibre type composites.

\section{References}

1. Wambua P, Ivens J and Verpoest I. Natural fibres: can they replace glass in fibre reinforced plastics? Composites Science and Technology 2003; 63: 1259-1264.

2. Faruk O, Bledzki AK, Fink H-P, et al. Biocomposites reinforced with natural fibers: 2000 2010. Progress in Polymer Science 2012; 37: 1552-1596. DOI: https://doi.org/10.1016/j.progpolymsci.2012.04.003.

3. Faruk O, Bledzki AK, Fink H-P, et al. Progress report on natural fiber reinforced composites. Macromolecular Materials and Engineering 2014; 299: 9-26. DOI: 10.1002/mame.201300008.

4. Pickering KL, Efendy MGA and Le TM. A review of recent developments in natural fibre composites and their mechanical performance. Composites Part A: Applied Science and Manufacturing 2016; 83: 98-112. DOI: http://dx.doi.org/10.1016/j.compositesa.2015.08.038. 5. Dong C. Review of natural fibre-reinforced hybrid composites. Journal of Reinforced Plastics and Composites 2018; 37: 331-348. DOI: 10.1177/0731684417745368.

6. Dong C and Davies IJ. Optimal design for the flexural behaviour of glass and carbon fibre reinforced polymer hybrid composites. Materials \& Design 2012; 37: 450-457. DOI: http://dx.doi.org/10.1016/j.matdes.2012.01.021.

7. Dong $\mathrm{C}$ and Davies IJ. Flexural properties of glass and carbon fiber reinforced epoxy hybrid composites. Proceedings of the Institution of Mechanical Engineers, Part L: Journal of Materials Design and Applications 2013; 227: 308-317.

8. Dong C and Davies IJ. Flexural and tensile strengths of unidirectional hybrid epoxy composites reinforced by S-2 glass and T700S carbon fibres. Materials \& Design 2014; 54: 955-966. DOI: http://dx.doi.org/10.1016/j.matdes.2013.08.087. 
9. Dong $\mathrm{C}$ and Davies IJ. Flexural and tensile moduli of unidirectional hybrid epoxy composites reinforced by S-2 glass and T700S carbon fibres. Materials \& Design 2014; 54: 893-899. DOI: http://dx.doi.org/10.1016/j.matdes.2013.08.086.

10. Dong $\mathrm{C}$ and Davies IJ. Flexural strength of bidirectional hybrid epoxy composites reinforced by E glass and T700S carbon fibres. Composites Part B: Engineering 2015; 72: 65-71. DOI: http://dx.doi.org/10.1016/j.compositesb.2014.11.031.

11. Dong C, Duong J and Davies IJ. Flexural properties of S-2 glass and TR30S carbon fiberreinforced epoxy hybrid composites. Polymer Composites 2012; 33: 773-781.

12. Dong C, Ranaweera-Jayawardena HA and Davies IJ. Flexural properties of hybrid composites reinforced by S-2 glass and T700S carbon fibres. Composites Part B: Engineering 2012; 43: 573-581. DOI: 10.1016/j.compositesb.2011.09.001.

13. Dong C, Sudarisman and Davies IJ. Flexural properties of E glass and TR50S carbon fiber reinforced epoxy hybrid composites. Journal of materials engineering and performance 2013; 22: 41-49.

14. Srinivasan VS, Rajendra Boopathy S, Sangeetha D, et al. Evaluation of mechanical and thermal properties of banana-flax based natural fibre composite. Materials \& Design 2014; 60: 620627. DOI: http://dx.doi.org/10.1016/j.matdes.2014.03.014.

15. Boopalan M, Niranjanaa M and Umapathy MJ. Study on the mechanical properties and thermal properties of jute and banana fiber reinforced epoxy hybrid composites. Composites Part B: Engineering 2013; 51: 54-57. DOI: http://dx.doi.org/10.1016/j.compositesb.2013.02.033.

16. Alavudeen A, Rajini N, Karthikeyan S, et al. Mechanical properties of banana/kenaf fiberreinforced hybrid polyester composites: Effect of woven fabric and random orientation. Materials \& Design 2015; 66, Part A: 246-257. DOI: http://dx.doi.org/10.1016/j.matdes.2014.10.067.

17. Senthil Kumar K, Siva I, Rajini N, et al. Layering pattern effects on vibrational behavior of coconut sheath/banana fiber hybrid composites. Materials \& Design 2016; 90: 795-803. DOI: https://doi.org/10.1016/j.matdes.2015.11.051.

18. Venkateshwaran N, ElayaPerumal A, Alavudeen A, et al. Mechanical and water absorption behaviour of banana/sisal reinforced hybrid composites. Materials \& Design 2011; 32: 4017-4021. DOI: https://doi.org/10.1016/j.matdes.2011.03.002.

19. Xiong X, Shen SZ, Hua L, et al. Finite element models of natural fibers and their composites: A review. Journal of Reinforced Plastics and Composites 2018; 37: 617-635. DOI: 10.1177/0731684418755552.

20. Sapuan SM, Leenie A, Harimi M, et al. Mechanical properties of woven banana fibre reinforced epoxy composites. Materials \& Design 2006; 27: 689-693. DOI: https://doi.org/10.1016/j.matdes.2004.12.016.

21. Bledzki AK and Gassan J. Composites reinforced with cellulose based fibres. Progress in Polymer Science 1999; 24: 221-274. DOI: https://doi.org/10.1016/S0079-6700(98)00018-5.

22. Baley C, Perrot Y, Busnel F, et al. Transverse tensile behaviour of unidirectional plies reinforced with flax fibres. Materials Letters 2006; 60: 2984-2987. DOI:

http://dx.doi.org/10.1016/i.matlet.2006.02.028.

23. Gentles F, Anderson J and Thomason J. Characterisation of the transverse thermoelastic properties of natural fibres used in composites. In: 14th European Conference on Composite Materials, ECCM14 2010.

24. Takao Y and Taya M. Thermal expansion coefficients and thermal stresses in an aligned short fiber composite with application to a short carbon fiber/aluminum. ASME, Transactions, Journal of Applied Mechanics 1985; 52: 806-810.

25. Taya M and Chou TW. On two kinds of ellipsoidal inhomogeneities in an infinite elastic body: an application to a hybrid composite. International Journal of Solids and Structures 1981; 17 : 553-563. 
26. Eshelby JD. The determination of the elastic field of an ellipsoidal inclusion, and related problems. Proceedings of the Royal Society of London Series A Mathematical and Physical Sciences 1957; 241: 376-396.

27. Mori T and Tanaka K. Average stress in matrix and average elastic energy of materials with misfitting inclusions. Acta metallurgica 1973; 21: 571-574.

28. Moigne NL, Oever Mvd and Budtova T. A statistical analysis of fibre size and shape distribution after compounding in composites reinforced by natural fibres. Composites Part A: Applied Science and Manufacturing 2011; 42: 1542-1550. DOI: https://doi.org/10.1016/j.compositesa.2011.07.012.

29. El-Shekeil YA, Sapuan SM, Abdan K, et al. Influence of fiber content on the mechanical and thermal properties of Kenaf fiber reinforced thermoplastic polyurethane composites. Materials \& Design 2012; 40: 299-303. DOI: https://doi.org/10.1016/j.matdes.2012.04.003.

30. Kardos JL. Critical issues in achieving desirable mechanical properties for short fiber composites. Pure and Applied Chemistry. 1985, p. 1651.

31. Baiardo M, Zini E and Scandola M. Flax fibre-polyester composites. Composites Part A: Applied Science and Manufacturing 2004; 35: 703-710. DOI:

https://doi.org/10.1016/j.compositesa.2004.02.004.

32. Noorunnisa Khanam P, Mohan Reddy M, Raghu K, et al. Tensile, Flexural and Compressive Properties of Sisal/Silk Hybrid Composites. Journal of Reinforced Plastics and Composites 2007; 26: 1065-1070. DOI: 10.1177/0731684407079347.

33. Standard Test Method for Flexural Properties of Polymer Matrix Composite Materials. 34. Hajianmaleki M and Qatu MS. Mechanics of composite beams. INTECH Open Access Publisher, 2011.

35. Bullock RE. Strength ratios of composite materials in flexure and in tension. Journal of Composite Materials 1974; 8: 200-206.

36. Arthanarieswaran VP, Kumaravel A and Kathirselvam M. Evaluation of mechanical properties of banana and sisal fiber reinforced epoxy composites: Influence of glass fiber hybridization. Materials \& Design 2014; 64: 194-202. DOI:

http://dx.doi.org/10.1016/j.matdes.2014.07.058.

37. Shanmugam D, Thiruchitrambalam $\mathrm{M}$ and Thirumurugan R. Continuous unidirectional palmyra palm leaf stalk fiber/glass_- polyester composites: static and dynamic mechanical properties. Journal of Reinforced Plastics and Composites 2014; 33: 836-850. DOI:

10.1177/0731684413518828.

38. Shanmugam D and Thiruchitrambalam M. Static and dynamic mechanical properties of alkali treated unidirectional continuous Palmyra Palm Leaf Stalk Fiber/jute fiber reinforced hybrid polyester composites. Materials \& Design 2013; 50: 533-542. DOI:

https://doi.org/10.1016/j.matdes.2013.03.048. 